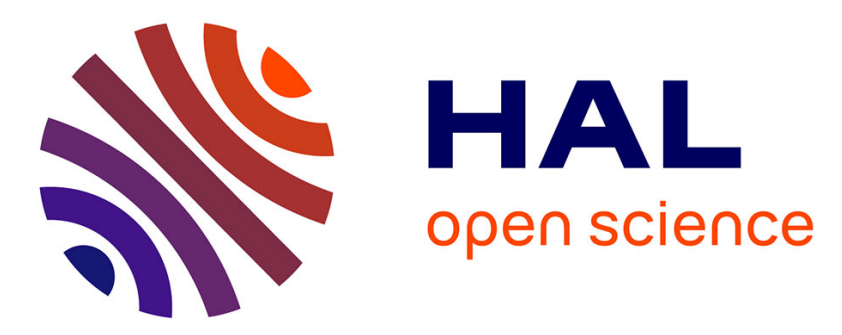

\title{
Four new cases of double heterozygosity for and gene mutations: clinical, pathological, and family characteristics
}

Monica Zuradelli, Bernard Peissel, Siranoush Manoukian, Daniela Zaffaroni, Monica Barile, Valeria Pensotti, Ugo Cavallari, Giovanna Masci, Frederique Mariette, Anne Caroline Benski, et al.

\section{To cite this version:}

Monica Zuradelli, Bernard Peissel, Siranoush Manoukian, Daniela Zaffaroni, Monica Barile, et al.. Four new cases of double heterozygosity for and gene mutations: clinical, pathological, and family characteristics. Breast Cancer Research and Treatment, 2010, 124 (1), pp.251-258. 10.1007/s10549010-0853-8 . hal-00526204

\section{HAL Id: hal-00526204 https://hal.science/hal-00526204}

Submitted on 14 Oct 2010

HAL is a multi-disciplinary open access archive for the deposit and dissemination of scientific research documents, whether they are published or not. The documents may come from teaching and research institutions in France or abroad, or from public or private research centers.
L'archive ouverte pluridisciplinaire HAL, est destinée au dépôt et à la diffusion de documents scientifiques de niveau recherche, publiés ou non, émanant des établissements d'enseignement et de recherche français ou étrangers, des laboratoires publics ou privés. 
Monica Zuradelli ${ }^{1 *}$, Bernard Peissel ${ }^{2 *}$, Siranoush Manoukian $^{2}$, Daniela Zaffaroni², Monica Barile ${ }^{3}$, Valeria Pensotti ${ }^{4}$, Ugo Cavallari ${ }^{1}$, Giovanna Masci ${ }^{1}$, Armando Santoro ${ }^{1}$, Paolo Radice ${ }^{5,6}$

\section{Four new cases of double heterozygosity for $B R C A 1$ and $B R C A 2$ gene mutations: clinical, pathological and family characteristics}

${ }^{1}$ Unit of Medical Oncology and Hematology, Istituto Clinico Humanitas, Rozzano, Milan, Italy

${ }^{2}$ Unit of Medical Genetics, Department of Preventive and Predictive Medicine, Fondazione IRCCS Istituto Nazionale dei Tumori, Milan, Italy.

${ }^{3}$ Division of Cancer Prevention and Genetics, Istituto Europeo di Oncologia, Milan, Italy.

${ }^{4}$ Consortium for Genomics Technology (Cogentech), Milan, Italy

${ }^{5}$ Unit of Genetic Susceptibility to Cancer, Department of Experimental Oncology and Molecular Medicine, Fondazione IRCCS Istituto Nazionale dei Tumori, Milan, Italy

${ }^{6}$ IFOM,Fondazione FIRC di Oncologia Molecolare (IFOM)

*These authors contributed equally to the work

Correspondance to:

Monica Zuradelli, MD

Unità Operativa di Oncologia Medica ed Ematologia

Istituto Clinico Humanitas

Via Manzoni 56, 20089 Rozzano (Milano), Italy

Tel: + 39-02-8224 3518 Fax: +39-02-8224 6297

e-mail: monica.zuradelli@ humanitas.it 


\section{ABSTRACT}

Background: Double heterozygosity (DH) for BRCA1 and BRCA2 mutations is a very rare finding, particularly in non-Ashkenazi individuals, and only a few cases have been reported to date. In addition, little is known on the pathological features of the tumors that occur in DH cases and on their family history of cancer.

Methods: Four carriers of pathogenic mutations in both $B R C A 1$ and $B R C A 2$ were identified among women who underwent genetic counseling for hereditary susceptibility to breast and ovarian carcinoma at three different Italian institutions. Clinical, pathological and family history data were collected from medical records and during genetic counseling sessions.

Results: All identified DH cases developed breast carcinoma and three of them were also diagnosed with ovarian carcinoma. Mean ages of breast and ovarian cancer diagnosis were 42.7 and 48.6 years, respectively. The majority of breast cancers showed a BRCAl-related phenotype, being negative for hormone receptors and HER2. Two cases reported different gastrointestinal tumors among relatives.

Conclusions: Although the individuals described in the present study show more severe clinical features in comparison to previously reported $B R C A 1$ and $B R C A 2 \mathrm{DH}$ cases, our observations support the hypothesis of a non specific phenotype of DH cases in terms of age of disease onset. In addition, our observations indicate that in $\mathrm{DH}$ patients breast carcinogenesis appears to be driven mainly by the mutations in BRCA1. The possible as sociation of DH for BRCA gene mutations with gastrointestinal tumors is in keeping with previous reports, but needs to be confirmed by further analyses. 
Key words: cancer susceptibility, genetic counselling, BRCA1, BRCA2, double heterozigosity Abbreviations:

DH: Double heterozygosity

ER: Estrogen receptor

PgR: Progesterone receptor 


\section{INTRODUCTION}

Germline mutations in $B R C A 1$ and $B R C A 2$ genes predispose to familial and early onset breast and ovarian cancer. Since 1994 testing for these mutations is available in both diagnostic and research settings, selecting subjects according to their personal and family history of cancer. Another factor to be investigated in the ascertainment of individuals eligible to mutation screening is ethnic background. For example, in the Ashkenazi Jewish population, the likelihood of being a carrier of one of the three common BRCA1 and BRCA2 founder mutations (185delAG, 5382insC in BRCAl and $6174 \mathrm{delT}$ in BRCA2) is as high as 1 in 50 [1]. In particular, the frequency of the $185 \mathrm{delAG}$ mutation has been estimated at $1.05 \%$ [2,3], of the 5382 insC mutation at $0.1 \%$ [2,3] and of the 6174deIT mutation at $1.4 \%[3,4]$. Due to these frequencies, several cases of double heterozygosity (DH) for pathogenic mutations in both genes have been reported in this specific ethnic group [5-7]. In the non-Ashkenazi population, the estimated prevalence of $B R C A 1$ and $B R C A 2$ mutation carriers is $0.11 \%$ and $0.12 \%$, respectively [8], and, consequently, $\mathrm{DH}$ for pathogenic mutations in both genes is expected to be very rare (1 in 190.000).

To our knowledge, only approximately 40 individuals with DH in BRCA genes have been reported to date $[5,6,9-21]$. Their identification has important implications for genetic counseling, clinical follow-up and can improve our understanding of genotype/phenotype correlation and mutation interaction.

In the present study, we report four new Italian cases with deleterious mutations in both $B R C A I$ and BRCA2 genes and describe the pathological characteristics of tumors that occurred in these individuals and their family history of cancer. 


\section{METHODS}

Genetic counseling was performed at three different Italian institutions (Istituto Clinico Humanitas, Fondazione IRCCS Istituto Nazionale Tumori and Istituto Europeo di Oncologia) where probands from breast/ovarian cancer families were selected for mutation screening in BRCA genes according to previously reported inclusion criteria [22].

Genomic DNA was isolated from patients' peripheral blood according to standard protocols. Molecular analysis (amplification and sequencing of all BRCA 1 and BRCA 2 coding exons and splice sites) was carried out in a single molecular laboratory, at the IFOM-IEO campus, Milan, Italy. Mutation designation is according to the Breast Information Core (BIC) nomenclature (http://research.nhgri.nih.gov/bic/)

Clinical, pathological and family history data were collected from medical records and during genetic counseling sessions. 


\section{CASE REPORTS}

\section{Case no. 1}

The first case was a 43 years old woman from Northern Italy who referred to genetic counseling on July 2008, reporting a personal and family history of breast cancer. On December 2007 she underwent mammary ultrasound which showed a 3-cm mass in the left superior external quadrant. Preoperative percutaneous needle biopsy confirmed the presence of cancer. In January 2008, she underwent quadrantectomy and homolateral axillary dissection. The pathologist reported a poorly differentiated, stage II, triple negative metaplastic breast carcinoma, with high proliferative index (Ki67: 35-40\%) and necrotic foci. There were no tumor metastases in any of 18 axillary lymph nodes examined [table 1]. The patient completed subsequent adjuvant chemotherapy with six cycles of doxorubicin and cyclophosphamide and local radiotherapy. No adverse acute or chronic radiation reaction has occurred to date. She is currently alive at age 45 , in good health, with no evidence of disease after 25 months of follow up.

The patient reported a maternal family history of mammary tumor. The mother was diagnosed with a bilateral breast cancer at 48 years and died two years later, the maternal grandmother was diagnosed with a unilateral breast cancer at 70 years and died 5 years later. She also referred of a few other cases of the same disease among her mother's cousins, but she did not remember ages of onset and outcomes. Furthermore, she reported of a maternal uncle diagnosed with leukemia at 45 years who died one year later for progression of disease [fig 1].

The genetic analysis found two different mutations, one in BRCA1 (954delC; H279fs) and one in BRCA2 (8423T >G L2732X). Both introduce a premature stop codon and are, therefore, pathogenetic. To date, no other family member have consented to testing.

\section{Case no. 2}

The second case was a 35 years old woman from Mid-Southern Italy, who referred to genetic counseling, reporting a personal and family history of breast cancer. In January 2000, At age 30, she underwent a right quadrantectomy with homolateral axillary dissection and the pathologist 
documented a ductal breast cancer, medullar type, in the absence of hormonal receptors and of axillary lymph node involvement [table 1]. After conservative surgery, the patient completed adjuvant chemotherapy with six cycles of cyclophosphamide, methotrexate and 5-fluorouracil and local radiotherapy. Subsequently, she started hormonal therapy with tamoxifene that was interrupted after a few months due to intolerance. At age 36, she had prophylactic salpingooophorectomy with peritoneal washing and biopsies. Pathological examination revealed a bilateral ovarian serous papillary carcinoma, grade 2 . Following this observation, the patient underwent radical surgery and was found free of residual pathological disease. She refused the proposed adjuvant chemotherapy for personal reasons. At age 39, she developed a recurrent pelvic disease from ovarian cancer for which she underwent surgery and chemiotherapy with carboplatin and taxol Collaterally, at 31 years she was diagnosed with systemic scleroderma. She is currently alive at age 40 , with no evidence of disease.

The patient reported an impressive history of cancer in the paternal family [fig 2]. The father, from Central Italy, presented with a gastric cancer when he was 66 years old, his twin brother died of lung malignancy at age 61 , one of his sister presented a breast cancer when she was 50 years old and a contralateral breast cancer at age 53 and died one year later; another sister died of pancreatic cancer at age 51. The paternal grandmother died of lung neoplasm when she was 70 years old. In addition, the mother, from Southern Italy, was treated for preinvasive cervix carcinoma at age 35 and the maternal grandfather developed a colon cancer when he was 73 years old.

The genomic analysis demonstrated two truncating mutations in both BRCA1 and BRCA2 genes: 4035deITT (L1306fs) and 5608delG (Val1794X), respectively.

The mother tested negative for both mutations.

\section{Case no. 3}

The third case was a 63 years old woman from Northern Italy who attended genetic counseling in November 2007. At age 46, she developed two left breast cancer foci, confirmed at a cytological examination. She underwent lumpectomy and axillary dissection that revealed a poorly 
differentiated, infiltrating ductal breast cancer in both masses, in the absence of lymph node involvement. One node was positive for p53 (60\%), HER2 (30\%) and Ki67 (30\%) and negative for estrogen receptor (ER) and progesterone receptor $(\mathrm{PgR})$; the other one was negative for p53 and HER2 and positive for Ki67 (40\%), ER (60\%) and PgR (30\%). After surgery, she received local radiotherapy. At age 58, she underwent salpingo-oophorectomy for a moderately-differentiated, stage IIIC, serous papillary cistoadenocarcinoma (pT3c G2 pN1) [table 1]. After surgery, she started adjuvant chemotherapy with carboplatin and paclitaxel in another hospital and we were unable to obtain more details. Our last contact with her was in January 2008, when she reported no recurrence of disease.

The patient referred a positive family history of cancer [fig 3]. The mother developed a breast cancer when she was 73 years old and died at age 94 . She referred of a maternal aunt with breast cancer, a maternal uncle with colon cancer, one cousin with colon cancer at age 55, an another cousin who died at age 23 from unspecified tumor and two other maternal uncles with unspecified neoplasias, but she was not able to report more details. The maternal grandmother developed a gastric tumor at age 70 . The father died at age 68 , probably of leukemia, and a paternal aunt developed breast tumor when she was 60 years old. A brother had gastric cancer at age 48 .

The patient was found to carry two truncating mutations: 1806C>T (Q563X) in BRCA1 and 6697C $>\mathrm{T}(\mathrm{Q} 2157 \mathrm{X})$ in BRCA2.

Her healthy niece tested negative for both mutations.

\section{Case no. 4}

The fourth case was a 53 years old woman from Northern Italy who referred to genetic counseling in October 2008. She developed synchronous breast and ovarian cancers at age 52 years. At age 52, she underwent a left lumpectomy with a diagnosis of poorly differentiated, stage II, triple negative, ductal breast carcinoma, with focal, solid intraductal component, central necrosis, high proliferative index (Ki67: 80\%) and negative sentinel lymph nodes. In September 2007, she underwent salpingooophorectomy with hysterectomy, omentectomy, systemic lymphoadenectomy and peritoneal 
washing and biopsy for a poorly differentiated stage IIIC serous bilateral ovarian adenocarcinoma (pT3 pN1) [table 1].

After surgery she completed adjuvant chemotherapy with 12 cycles of carboplatin and paclitaxel and subsequent local radiotherapy. She is alive without evidence of disease at 29 months of followup.

The genomic analysis demonstrated two truncanting mutations, one in BRCA1 (2524delTG, V802fs) and the other in BRCA2 (4512insT; Q1429fs).

The sister, who also developed synchronous breast and ovarian cancer at 52 years, was screened for the presence of the above genetic alterations in another laboratory and tested positive for the BRCA1 mutation, but negative for the BRCA2 mutation. To date, no other family member has consented to testing. 


\section{DISCUSSION}

At present, a relatively small number of cases of $\mathrm{DH}$ for BRCA1 and BRCA2 mutations have been described. This is in keeping with the extremely low probability of having both genes mutated in the same individual. In addition, little is known on the pathological features of the tumors that occur in DH cases and on their family history of cancer.

Studies reporting data on the prevalence of DH in BRCA genes showed the Ashkenazi Jewish descent as the single most important predictor of this rare event [18]. In 2002, Frank et al. [17], describing the results of 10,000 consecutive gene sequence analysis, reported $11 \mathrm{DH}$ cases. The authors remarked that all of them were detected among 617 Ashkenazi mutation carriers (1.8\%), that corresponds to $0.36 \%$ of 3,022 tested index cases from this ethnic group. Three years later Leegte et al. [18] presented four new DH individuals and reviewed all published cases, including 34 women and one man from 25 different families. They confirmed the presence of at least one Ashkenazi founder mutation in 19 of them, and of the Dutch BRCAl founder mutation 2804delAA in two other families. In the remaining four families (two from Korea, one from Scotland and one from Spain) the mutations referred were not founder mutations. In the same year the first example of an Italian non-Ashkenazi DH cases for BRCA1 and BRCA2 genes was reported by Musolino A et al. [20]. Finally, three other DH cases of European descent and no Ashkenazi heritage were reported by Claus et al. [19] and Smith et al. [21].

The four DH cases here described were ascertained among 2650 non-Ashkenazi index cases (for the vast majority of Italian descent) that have been tested as of February 2010 for $B R C A 1$ e $B R C A 2$ mutations in our laboratory. Of these, $636(24,0 \%)$ were found to carry at least one deleterious or suspected deleterious mutation. The percentage of DH cases we observed $(0.62 \%$ of the mutated individuals and $0.15 \%$ of the total index cases) was lower than that observed among Ashkenazi Jews by Frank et al. [17], in keeping with the low frequency expected outside that population. Conversely, in the same study, no DH cases were observed among 6,724 non-Ashkenazi individuals [17]. This discrepancy respect to our data, although most likely due mainly to differences in the 
inclusion criteria adopted for BRCA gene testing, might suggest that in Italian breast/ovarian families the incidence of BRCA mutations is higher than in other populations. Interestingly, none of the identified DH patients was a carrier of known Italian founder mutations [23-25], and had mutations in common with each other. Two of the eight identified mutations (954delC in BRCAl and 5608delG in BRCA2) were not present in any of the index cases tested in our laboratory, The remaining 6 mutations recurred in one or more additional cases, being the BRCAl $1806 \mathrm{C}>\mathrm{T}$ substitution, observed in 11 other individuals, the most frequently detected.

By reviewing published data, Leegte and colleagues [18] concluded that when compared with available population-specific cancer risk in carriers of single BRCA gene mutations, DH individuals do not show a more severe phenotype with respect to age of disease onset, cumulative lifetime risk and multiple primary tumors.

These authors reported a phenotypic expression in 34 women with DH, mostly of Ashkenazy Jews ancestry, varying from unilateral breast cancer at age 26 to cancer-free survival at age 70 . In their review, 10 mutations carriers $(29.4 \%$ ), were without cancer at a mean age of 51.3 years (range 36 to 70); the other 24 women (70.6\%) developed 32 primary cancers (26 breast and 6 ovarian) at a mean onset age of 42.3 years (range 26 to 70 ). The mean age at diagnosis for breast cancers was 41.1 years (range 26 to 70 ) and for ovarian cancers 45.7 years (range 36 to 57). In 13 women (54\% of affected cases) the first cancer was diagnosed before the age of 40 . Three women had bilateral breast cancer (mean age 40.7- mean age 33 to 55) and one had three primary breast cancers (at age 33, 44 and 47). Three women developed both breast and ovarian cancers $(8,8 \%$, mean age of first cancer 39.3 years, range 30 to 48). Three women had ovarian cancer only (mean age 47.7 yearsrange 36 to 57). The age related incidence for first cancer was $84 \%$ (confidence interval (CI),38\% to 99\%) at age 70, and median cancer-free survival was 45 years (range 33 to 57).

Compared to the above series, our $4 \mathrm{DH}$ cases showed, on average, a more severe phenotype, since 3 of them (75\%) developed both a breast and an ovarian cancer, being the only exception a patient who was diagnosed with breast cancer at 43 years and had a brief follow-up (ca. 2 years). 
Conversely, the mean age at breast and ovarian cancer diagnosis (42.7 and 48.7 years, respectively) was similar to that reported by Leedge et al. [18], and none of them developed contralateral breast cancer. The differences observed between the two series could be due several factors, including the small number of individuals reported and ascertainment biases. The different genetic background should also be considered, as variations in disease risk are described in population with known founder mutations.

Both $B R C A 1$ and $B R C A 2$ related breast carcinomas are usually of high grade. However, while there are no known histopathological features that distinguish $B R C A 2$ from sporadic tumors, breast cancers occurring in carriers of BRCAl mutations are usually negative for the expression of ER, PgR and of HER2 (the so-called 'triple-negative' phenotype) and positive for of p53 alterations [26]. As reported in table 1, the breast cancers that occurred in our DH cases were all high grade, stage II, mostly negative for hormonal receptors and/or HER expression and with high proliferative index. These data indicate that breast cancers in $\mathrm{DH}$ cases are more likely to exhibit a BRCAI histopatological phenotype and suggest that in these patients breast carcinogenesis is mainly driven by the mutations in BRCA1, even if this hypothesis requires confirmatory studies on a larger number of cases.

The penetrance of mutations within BRCA1 and BRCA2 genes can be incomplete and their expressivity can be variable determining very different phenotypes even in members of the same family sharing the same genetic alteration [16,21]. Case no. 4 had a sister, who although carrier of only one of the two identified mutations, exhibited an astonishingly identical phenotype, that is synchronous breast and ovary carcinomas developed at the very same age (52 years), but no other cancer cases in the family. Conversely, the remaining three cases here described (nos. 1 to 3 ) reported a positive family for breast cancer with one ore more affected relatives and for a variety of other cancers, although the relation with the DH status remains unclear, since very few segregation data are available. 
Interestingly, both cases no. 2 and no. 3 reported the occurrence of different gastrointestinal tumors in the family, including gastric, pancreatic and colon carcinomas. Indeed, the occurrence of gastrointestinal malignancies in relatives of $B R C A 1 / B R C A 2 \mathrm{DH}$ individuals has been already described. Musolino et al. [20] reported gastric cancer in the father and in the maternal grandfather of the DH case they described, but their mutation status was unknown. Of the two DH cases reported by Choi et al. [16], one developed breast cancer at age 26 and her mother, carrier of both mutations, was diagnosed with gastric cancer at age 62. Finally, Smith et al [21] described two sister with BRCA1 and BRCA2 DH, one of whom developed breast cancers at age 34 and 53 and a moderately differentiated carcinoma of the trans verse colon at the age of 35, that tested negative for microsatellite instability. The paternal side of the family exhibited a typical pattern of hereditary breast/ovarian cancer, consistent with a predisposing mutation in BRCA gene. However, no family member consented to testing. The mother had ovarian cancer at age 47 , her family was suggestive of Hereditary Non Polyposis Colorectal Cancer (HNPCC), meeting the modified Amsterdam criteria [27]. One maternal relative, who developed colon cancer at age 68 tested negative for both mutations. While the specific cancer risks of carriers of pathogenic mutations in both BRCAl and BRCA2 remains to be established, the possible association of DH in BRCA genes with gastrointestinal tumors warrant further analysis, in order to provide medical geneticists and oncologists with appropriate risk figures and shared guidelines.

Finally, although DH in BRCA genes appears to occur infrequently, with the possible exception of the Askenazi Jews, our results strengthen the notion that, when testing for hereditary susceptibility to breast/ovarian cancers, it is always recommendable to complete the entire screening of both BRCA1 and BRCA2. In fact, in the absence of personal or familial features predictive of DH status, stopping the analyses when a single pathogenic mutation is identified prevents the ascertainment of individuals with mutations in both BRCA genes and may lead to erroneous risk estimates, following incomplete predictive testing of their relatives. 
Acknowledgements: This study was supported by grants from Fondazione Italiana per la Ricerca sul Cancro (Special Project "Hereditary tumors"), Ministero della Salute ("Progetto Tumori Femminili”), and by funds from Italian citizens who allocated the $5 \times 1000$ share of their tax payment in support of the Fondazione IRCCS Istituto Nazionale Tumori (INT), according to Italian laws (INT-Institutional strategic projects “5x1000”). 


\section{REFERENCES}

1) Hartge P, Struewing JP, Wacholder S, Brody LC, Tucker MA (1999) The prevalence of common BRCA1 and BRCA2 mutations among Ashkenazi Jews. Am J Hum Genet 64:963970.

2) Struewing J, Abeliovich D, Peretz T, Avishai N, Kaback MM, Collins FS, Brody LC (1995) The carrier frequency of the BRCA1 $185 \mathrm{delAG}$ mutation is approximately 1 percent in Ashkenazi Jewish individuals. Nat Genet 11:198-200.

3) Roa B, Boyd A, Volcik K, Richards CS (1996) Ashkenazi Jewish population frequencies for common mutations in BRCA1 and BRCA2. Nat Genet 14:185-187.

4) Oddoux C, Struewing J, Clayton C, Neuhausen S, Brody LC, Kaback M, Haas B, Norton L, Borgen P, Jhanwar S, Gold gar D, Ostrer H, Offit K (1996) The carrier frequency of the BRCA2 6174delT mutation among Ashkenazi Jewish individuals is approximately $1 \%$. Nat Genet 14:188-190.

5) Randall TC, Bell KA, Rebane BA, Rubin SC, Boyd J (1998) Germline mutations of the BRCA1 and BRCA2 genes in a breast and ovarian cancer patient. Gynecol Oncol 70:432434.

6) Friedman E, Bar-Sade Bruchim R, Kruglikova A, Risel S, Levy-Lahad E, Halle D, Bar-On E, Gershoni-Baruch R, Dagan E, Kepten I, Peretz T, Lerer I, Wienberg N, Shushan A, Abeliovich AD (1998) Double heterozygotes from the Ashkenazi founder mutations in BRCA1 and BRCA2 genes. Am J Hum Genet 63:1224-1227.

7) Gershoni-Baruch R, Dagan E, Kepten I, Freid G (1997) Co-segregation of BRCAI 185delAG mutation and BRCA2 6174delT in one single family. Eur J Cancer 33:2283-2284.

8) Peto J, Collins N, Barfoot R, Seals S, Warren W, Rahman N, Easton DF, Evans C, Deacon J, Stratton MR (1999) Prevalence of BRCA1 and BRCA2 gene mutations in patients with early-onset breast cancer. J of Ntl Cancer Inst 91:943-9 
9) Loader S, Rowley PT (1998) Deleterious mutations of both BRCA1 and BRCA2 in three siblings. Genet test 2:75-7

10) Ramus SJ, Friedman LS, Gayther SA, Ponder BA, Bobrow L, van der Looji M, Papp J, Olah E (1997) A breast/ovarian cancer patient with germilne mutations in both BRCAl and BRCA2. Nat Genet 15:14-15.

11) Liede A, RehalP, Vesprini D, Jack E, Abrahamson J, Narod SA (1998) A breast cancer patient of Scottish descent with germline mutations in BRCA1 and BRCA2. Am J Hum Genet 62:1543-1544.

12) Tesoriero A, Andersen C, Southey M, Somers G, McKay M, Armes J, McCredie M, Giles G, Hopper JL, Venter D (1999) De novo BRCA1 mutation in a patient with breast cancer and an inherited BRCA2 mutation. Am J Hum Genet 65:567-9

13) Moslehi R, Russo D, Phelan C, Jack E, Antman K, Narod S (2000) An unaffected individual from a breast/ovarian cancer family with germline mutations in both BRCA1 and BRCA2. Clin Genet 57:70-3.

14) Bell DW, Erban J, Sgroi DC, Haber DA (2002) Selective loss oh heterozygosity in multiple breast cancers froma a carrier of mutations in both $B R C A 1$ and $B R C A 2$. Cancer Res 62: 2741-3.

15) Caldes T, de la Hoya M, Tosar A, Sulleiro S, Godino J, Ibañez D, Martin M, Perez-Segura P, Diaz-Rubio E (2002) A breast cancer family from Spain with germline mutations in both the BRCA1 and BRCA2 genes. J Med Genet Aug;39(8):e44.

16) Choi DH, Lee MH, Bale AE, Carter D, Haffty BG (2004) Incidence of BRCAI and BRCA2 mutations in young Korean breast cancer patients. J Clin Oncol 22:1638-45.

17) Frank TS, Deffenbaugh AM, Reid JE, Hulick M, Ward BE, Lingenfelter B, Gumpper KL, Scholl T, Tavtigian SV, Pruss DR, Critchfield GC (2002) Clinical characteristics of individuals with germline mutations in BRCA 1 and BRCA 2: analysis of 10.000 individuals. J Clin Oncol 20:1480-1490. 
18) Leegte B, van der Hout A H, Deffenbaugh AM, Bakker MK, Mulder IM, ten Berge A, Leenders EP, Wesseling J, de Hullu J, Hoogerbrugge N, Ligtenberg MJ, Ardern-Jones A, Bancroft E, Salmon A, Barwell J, Eeles R, Oosterwijk JC (2005) Phenotypic expression od double heterozygosity for BRCA 1 and BRCA2 germline mutations. J Med Genet 42:e20

19) Claus EB, Petruzella S, Matloff E, Carter D (2005) Prevalence of BRCA1 and BRCA2 mutations in women diagnosed with ductal carcinoma in situ. JAMA 293:964-69.

20) Musolino A, Naldi N, Michiara M, Bella MA, Zanelli P, Bortesi B, Cappelletti M, Savi M, Neri TM, Ardizzoni A (2005) A breast cancer patient from Italy with germline mutations in both the BRCA1 and BRCA2 genes. Breast Cancer Research and Treatment 91:203-205.

21) Smith M, Fawcett S, Sigalas E, Bell R, Devery S, Andrieska N, Winship I (2008) Familial breast cancer: double heterozygosity for $B R C A 1$ and $B R C A 2$ mutations with differing phenotypes. Familial Cancer 7:119-124.

22) Manoukian S, Peissel B, Pensotti V, Barile M, Cortesi L, Stacchiotti S, Terenziani M, Barbera F, Pasquini G, Frigerio S, Pierotti MA, Radice P, Della-Torre G (2007) Germline mutations of TP53 and BRCA2 genes in breast cancer/sarcoma families. Eur J Cancer 43:601-6.

23) Caligo MA, Ghimenti C, Cipollini G, Ricci S, Brunetti I, Marchetti V, Olsen R, Neuhausen S, Shattuck-Eidens D, Conte PF, Skolnick MH, Bevilacqua G (1996) BRCA1 germline mutational spectrum in Italian families from Tuscany: a high frequency of novel mutations. Oncogene 13:1483-1488.

24) Baudi F, Quaresima B, Grandinetti C, Cuda G, Faniello C, Tassone P, Barbieri V, Bisegna R, Ricevuto E, Conforti S, Viel A, Marchetti P, Ficorella C, Radice P, Costanzo F, Venuta S (2001) Evidence of a founder mutation of $B R C A l$ in a highly homogeneous population from southern Italy with breast/o varian cancer. Hum Mutat 18:163-164.

25) Papi L, Putignano AL, Congregati C, Zanna I, Sera F, Morrone D, Falchetti M, Turco MR, Ottini L, Palli D, Genuardi M Founder mutations account for the majority of BRCA1- 
attributable hereditary breast/ovarian cancer cases in a population from Tuscany, Central Italy (200) Breast Cancer Res Treat. doi: 10.1007/s10549-008-0190-3

26) Phillips KA (2000) Immunophenotypic and pathologic differences between $B R C A 1$ and BRCA2 hereditary breast cancers. J Clin Oncol 18:107-112.

27) Svendsen LB, Sønderggard JO, Bernstein IT, Bisgaard ML, Myrhøj T, Bülow S. Hereditary non-polyposis colorectal cancer. Ugeskr Laeger. 1192 Mar30; 154 (14): 917-20. 
Table 1. Pathological and histopathological characteristics of breast and ovarian cancers of DH cases.

\section{Case no.}

\begin{tabular}{lll}
\hline 1 & 2 & 3
\end{tabular}

Breast cancer

Age at initial diagnosis

Laterality

Multifocality

TNM stage

Number of involved lymph nodes

His tological grade

His tology

Proliferation index (Ki67\%)

Estrogen receptor status

Progesterone receptor status

HER2 status

\section{Ovarian cancer}

Age at initial diagnosis

Stage

His tological grade

His tology
43

Unilateral

No

II

$0 / 18$

3

Metaplastic

$35-40$

Negative

Negative

Negative
30

Unilateral

No

II

$0 / 32$

3

Medullary

n.a.

Negative

Negative

n.a.

36

$?$

2

Serous papillary
46

Unilateral

Yes

II

$0 / 12$

$3 ; 3$

Ductal; Ductal $30 ; 40$

Negative; Positive

Negative; Positive

Positive; Negative 



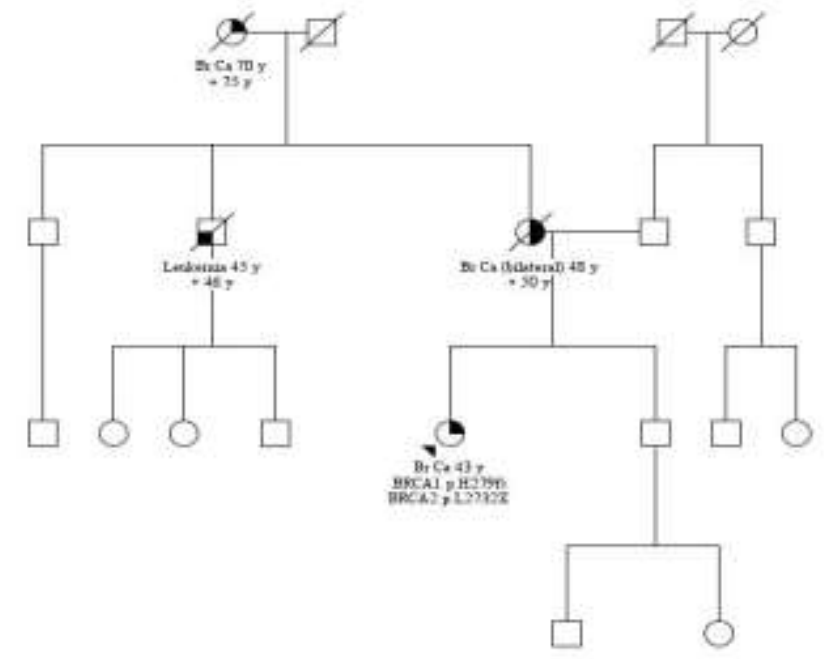

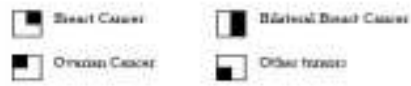

Fig. 1 Pedigree of case $n^{\circ} 1$ 
matex $z$

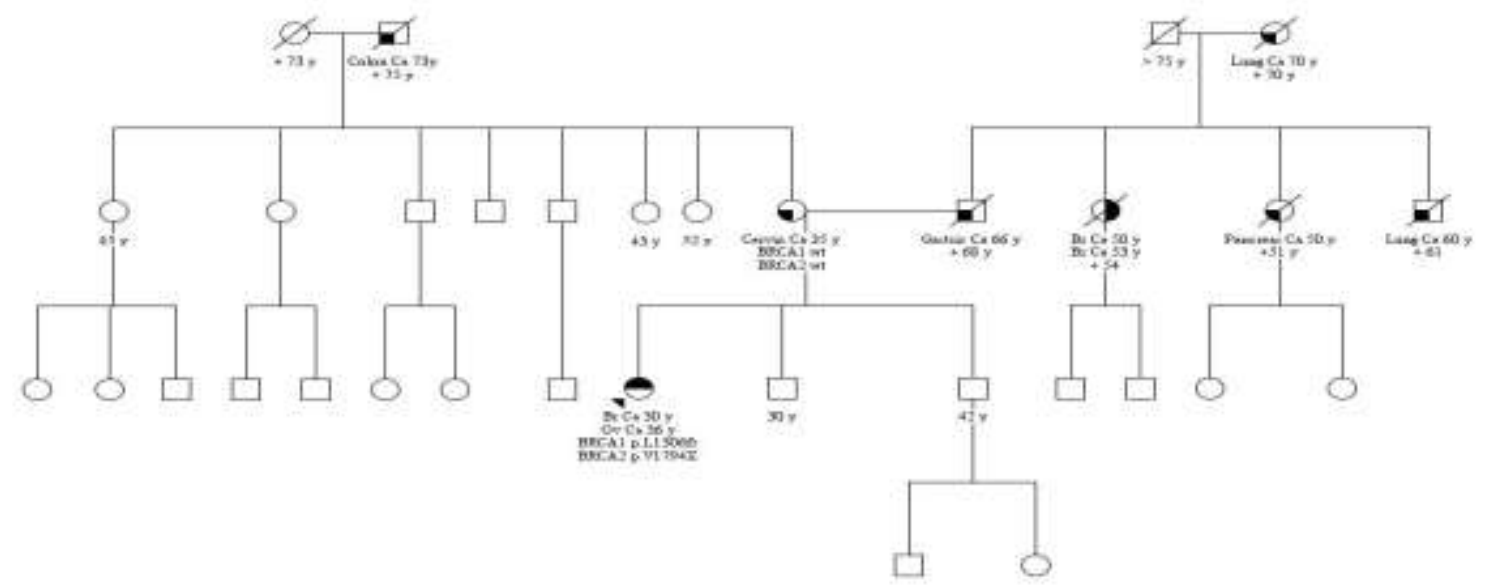

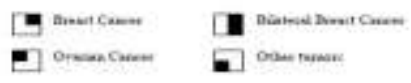

Fig. 2 Pedigree of case $n^{\circ} 2$ 
Index 3

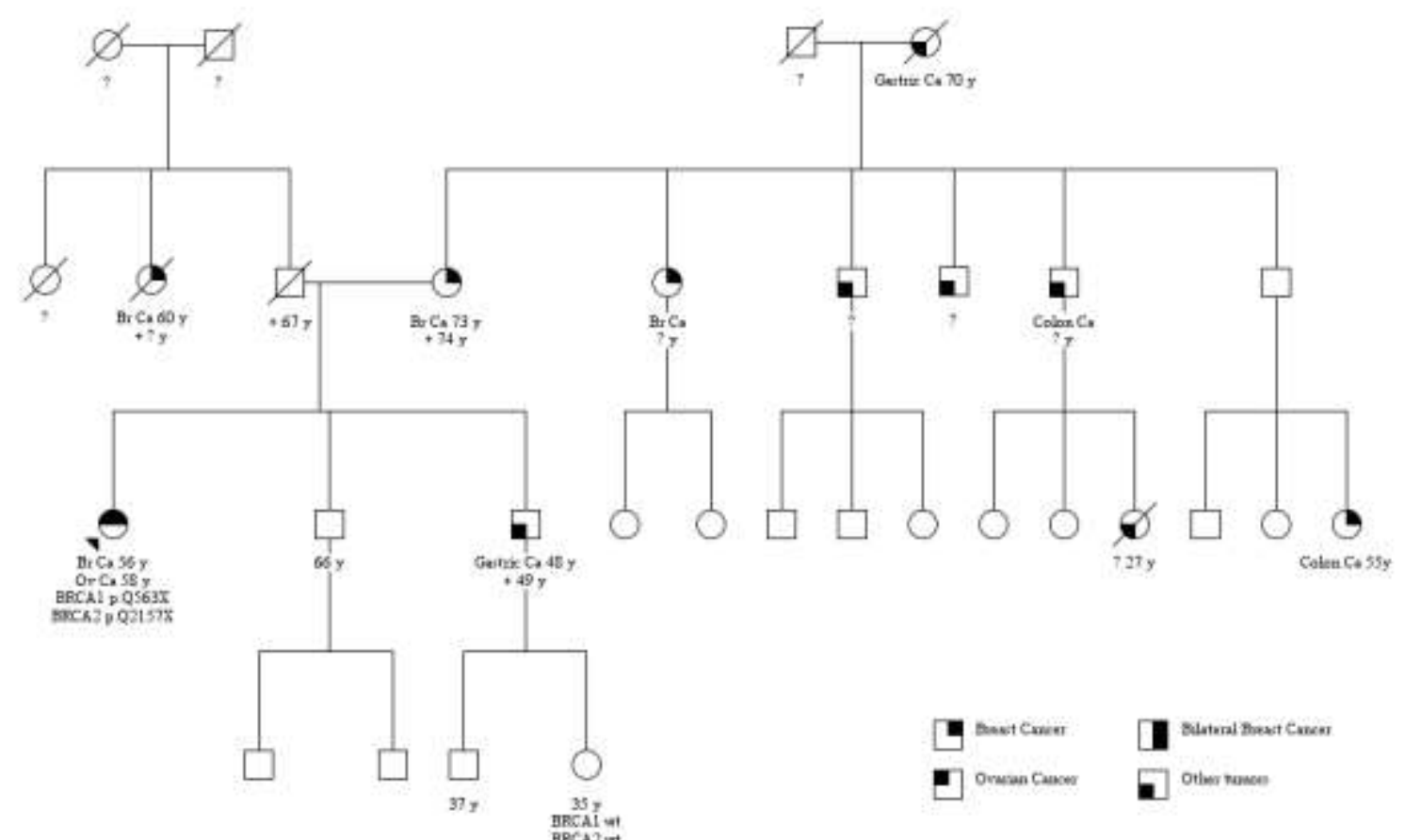

Fig. 3 Pedigree of case $n^{\circ} 3$ 

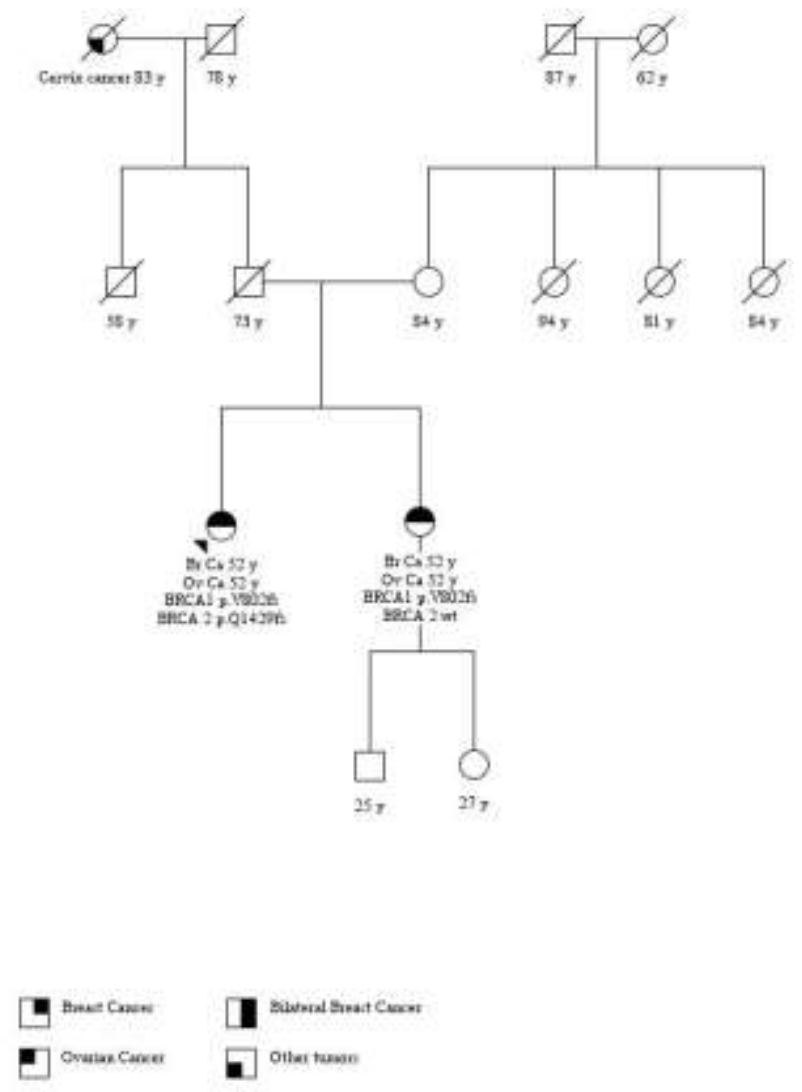

Fig. 4 Pedigree of case $n^{\circ} 4$ 